\title{
Segundo Storni, el mar y la desespacialización de la política
}

\author{
Gerardo TRIPOLONE \\ Consejo Nacional de Investigaciones Científicas y Técnicas (Conicet) (Argentina) \\ Universidad Nacional de San Juan (Argentina) \\ gerardo.tripolone@gmail.com
}

Recibido: 17-02-2015

Aceptado: $30-06-2015$

\begin{abstract}
RESUMEN
Una de las obras fundacionales de la geopolítica argentina es Intereses argentinos en el mar, del vicealmirante Segundo Storni. Publicada en 1916, el autor defiende en ella el carácter insular de Argentina y, por tanto, la necesidad de tomar el mar como elemento y abandonar la visión terrestre que había caracterizado al país. Esta tesis ha repercutido profundamente en el pensamiento naval posterior y, salvo la aislada crítica del general Guglialmelli, no ha sido puesta en cuestión. El objetivo de este trabajo es realizar una revisión crítica de la tesis principal de Storni. A poco de cumplirse 100 años de la publicación, una relectura es pertinente, ya que la posición del autor acarrea consecuencias que deben explicitarse. La más importante de ellas es la radicalización del proceso de desespacialización de la política y deslocalización de Argentina con respecto al continente.
\end{abstract}

Palabras clave: Argentina; pensamiento geopolítico; geopolítica marítima; desespacialización; deslocalización.

\section{Segundo Storni, the sea and the de-spatialization of politics}

\begin{abstract}
A landmark work of Argentinian geopolitics is Intereses argentinos en el mar, by Vice-Admiral Segundo Storni. Published in 1916, the author defends the idea that, based on the country's insularity, the sea (and not the land) shall be the element that orients Argentina's vision of the world. Having had a long-lasting influence on naval thought, this thesis has not been rebutted by anyone except for General Guglialmelli. The aim of this work is to offer a critical revision of Storni's main thesis. Almost 100 years after its publication, its re-reading becomes all the more important for the author's standpoint has implications that need to be further examined - the most important amongst them being the radicalization of the de-spatialization of politics and the de-localization of Argentina vis-à-vis the rest of the continent-.
\end{abstract}

Key words: Argentine; geopolitical thinking; sea geopolitics; de-spatialization; de-localization.

\section{Segundo Storni, o mar e a desespacialização da política}

\section{RESUMO}

Uma das obras fundacionais da geopolítica argentina é Interesses argentinos no mar, do vice-almirante Segundo Storni. Publicada em 1916, o autor defende nela o carácter insular de Argentina e, por tanto, a necessidade de tomar o mar como elemento e abandonar a visão terrestre que tinha caracterizado ao país. 
Esta tese tem repercutido profundamente no pensamento naval posterior e, salvo a isolada crítica do general Guglialmelli, não tem sido posta em questão. O objetivo deste trabalho é realizar uma revisão crítica da tese principal de Storni. A pouco de cumprir-se 100 anos da publicação, uma releitura é apropriada, já que a posição do autor acarreta consequências que devem explicitar-se. A mais importante delas é a radicalização do processo de desespacialização da política e deslocalização de Argentina com respeito ao continente.

Palavras-chave: Argentina; pensamento geopolítico; geopolítica marítima; desespacialização; deslocalização.

\section{REFERENCIA NORMALIZADA}

Tripolone, Gerardo (2015) "Segundo Storni, el mar y la desespacialización de la política". Geopolítica(s).

Revista de estudios sobre espacio y poder, vol. 6, núm. 1, 137-152.

SUMARIO: Introducción. 1. Sus influencias. 2. Su repercusión. 3. Argentina marítima. 4. La crítica de Guglialmelli. 5. La toma del mar y la desespacialización de la política. A modo de cierre. Bibliografía.

\section{Introducción}

En junio de 1916 el vicealmirante Segundo Storni pronunció dos conferencias que lo llevarían a ser uno de los exponentes máximos de la geopolítica argentina. Publicadas parcialmente en el diario La Prensa, adquirirían su forma definitiva en el libro Intereses argentinos en el mar. Storni ya había publicado algunos textos sobre oceanografía y geopolítica marítima, como Trabajos hidrográficos y límite argentino en el canal de Beagle (1905) y Proyecto de régimen de mar territorial (1911). No obstante, no caben dudas de que Intereses argentinos en el mar es la obra de mayor importancia en su pensamiento geopolítico.

Las dos conferencias reunidas en el volumen fueron editadas en 1916 y reeditadas oficialmente en 1952 y 2009, más la publicación que el Instituto de Publicaciones Navales de Argentina realizó en 1967. El autor aclara reiteradamente que las conferencias tienen carácter general y están dirigidas a militares, estadistas, políticos y civiles en general. Plantea un abordaje panorámico de la situación de Argentina y su ubicación en el Atlántico Sur, estableciendo las líneas maestras de los desafíos geopolíticos del país.

En el primer texto, el autor aborda las razones de por qué Argentina debería preocuparse por el mar; cuáles son sus intereses en el mar y, sobre todo, los factores que "obstaculizan" y los que "facilitan" el desarrollo del poder naval de nuestro país. La segunda conferencia está dedicada a la cuestión de la defensa del mar y, con él, de todo el territorio y los intereses de la Nación.

En el presente trabajo nos interesa estudiar críticamente la tesis central de la primera conferencia, esto es, la necesidad de afianzar y crear una conciencia colec- 
tiva sobre el carácter marítimo de Argentina. Partiendo de la ubicación geográfica alejada de los centros del comercio y la "civilización", según Storni, a nuestro país le corresponde un destino marítimo. Cuestiones geográficas, geopolíticas e incluso antropológicas se entrecruzan para afirmar la falta de esa conciencia marítima que retrasa la consolidación de un poder naval acorde con las expectativas de construcción de una potencia mundial. Dedicados a la tierra, los argentinos no tenían la preparación y la audacia necesaria para afrontar el mar, sus dificultades y desafíos.

La propuesta de Storni se basaba en un cambio de orientación no sólo política y económica, sino también cultural. Para el vicealmirante debía transformarse la visión que el pueblo tenía de su destino. La grandeza de Argentina estaba supeditada a la toma de conciencia del destino marítimo que las condiciones geográficas habían definido y el consecuente abandono de la visión terrestre que se había sostenido hasta entonces.

Una lectura crítica de esta tesis fundacional de la literatura geopolítica argentina es más que pertinente, sobre todo teniendo en cuenta que está muy cerca de cumplirse cien años de su publicación y es de notar la falta de estudios que pongan en cuestión los paradigmas filosófico-políticos que subyacen al pensamiento del vicealmirante. Con la relevante excepción de la lectura crítica realizada por el general Guglialmelli, que analizaremos más adelante, casi toda la literatura se hace eco de las propuestas stornianas sin debatir sus fundamentos.

Nuestra hipótesis es que, a pesar de lo que parece surgir a primera vista, la tesis de Storni en Intereses argentinos en el mar está fundada en un pensamiento que no toma en cuenta el espacio político argentino, sino que lo disuelve en la necesidad del comercio marítimo. El vicealmirante desespacializa la política al separar a nuestro país de Sudamérica y separar Buenos Aires (la ciudad-puerto) del interior. Aún más: separa al pueblo, esencialmente terrestre, del suelo que habita, llamando a cambiarlo culturalmente para que tome el mar como elemento. En definitiva, en pos de sostener y promover el comercio marítimo, Storni disuelve la espacialidad concreta de Argentina, una consecuencia de su tesis que no había sido resaltado hasta ahora.

\section{Sus influencias}

Segundo Storni nació en 1876 y se egresó de la Escuela Naval de Argentina en 1894. Esta ubicación temporal es sumamente importante, sobre todo para considerar sus influencias intelectuales. Una de ellas es fundamental: Alfred T. Mahan.

Mahan es reputado como el artífice del pensamiento naval moderno de Estados Unidos de Norteamérica. Suele afirmarse que fue él quien sentó las bases para que el país del norte construyese una gran flota mercante y de guerra, cimientos indudables - según su teoría - del poderío de las naciones. Su fama está relacionada con los dos libros titulados The influence of sea power, el primero de los cuales abarcó 
el periodo 1660-1793, publicado en 1890, y, el segundo, que comprende desde 1793 hasta 1812 , publicado en $1892^{1}$.

Filippo Ruschi habla de la "revolución mahaniana" como el punto en el que se produce un "abandono definitivo de la política «continental» practicada hasta entonces por Estados Unidos" (Ruschi, 2009: 102). Hasta ese momento, Estados Unidos habían orientado su mirada hacia el oeste. Su lucha contra el indio y contra México fue siempre una lucha terrestre, que le garantizó la expansión territorial y la conformación de un gran espacio que unió las costas del Pacífico con las del Atlántico. Con Alfred Mahan como principal autor intelectual, Estados Unidos se abre al mar.

Muy conocido en todo el mundo por estos desarrollos, Mahan falleció dos años antes de la publicación de Intereses argentinos en el mar. Como veremos más adelante, es posible afirmar que mucho de lo dicho por el argentino surge de la lectura del primer capítulo de The influence of sea power upon History, 1660-1793 (Mahan, 1890: 25-89).

La concepción de Mahan está basada en la premisa del dominio de los mares como instrumento de expansión geopolítica. Aunque la admiración es ex profeso - Storni cita a Mahan para avalar sus posturas en seis oportunidades-, el vicealmirante rechaza el expansionismo expresamente ${ }^{2}$. No obstante, lo que extrae de su par norteamericano es la necesidad del poder naval como base de la defensa nacional y como método eficaz de protección y promoción del comercio mundial.

Otra fuente importante es el pensamiento de Friedrich Ratzel. Esto puede sorprender ya que, en América del Sur, a Ratzel se lo conoce mucho más por su pensamiento continentalista basado, centralmente, en la geopolítica de Estados Unidos como arquetipo de Estado-continente (Barrios et al., 2009: 316). Su énfasis en el poder de los grandes espacios continentales - por oposición a los pequeños Estados atomizados-, hicieron del geógrafo alemán una fuente de inspiración tanto en su país natal como en América del Sur. Es por esto que es tenido en cuenta por la mayoría de los exponentes del pensamiento orientado hacia la construcción de un gran espacio sudamericano, cualquiera sea la corriente política a la que adhieran.

Sin embargo, lo que más le interesa a Storni de Ratzel es una serie de citas del libro Der Erde und das Leben, texto publicado en 1902. De esta obra, el vicealmirante argentino rescata la visión de Ratzel sobre el predominio y la influencia del mar sobre la población y la superioridad de miras de los pueblos que ven el mar como horizonte y no se quedan apegados a la tierra (Storni, 2009: 44 y 59-60). Esta

\footnotetext{
${ }^{1}$ Para una lectura crítica de Mahan, véase González Martín y Aznar Fernández-Montesinos (2013).

2 "Aunque alcancemos algún día los límites de la verdadera potencia, no la deseo [la política de expansionismo] para mi país; es una política de doble filo; engendra el irredentismo, que va, átomo por átomo, trabajando el alma de los pueblos, hasta producir esas olas de heroísmo y de sacrificio, que los conducen a las cruentas y sagradas reivindicaciones" (Storni, 2009: 91).
} 
posición es central en nuestro autor, ya que marca una diferencia antropológica entre el hombre de mar y el hombre dedicado a la tierra.

Relacionado con este punto y como tercera y última influencia importante para nuestro trabajo, cabe citar lo que señala la exministra de defensa de Argentina, prologuista de la edición del 2009 de Intereses argentinos en el mar, Nilda Garré. Según Garré, existe en el texto de Storni un cierto "darwinismo antropológico en boga en algunas corrientes hoy superadas" (Garré, 2009: 8). Esto es cierto en algún punto. Storni no hesita en señalar la superioridad de las gentes que han elegido el mar como elemento con respecto a quienes en definitiva poblaron nuestras tierras. Este darwinismo quizás se debe en parte a sus lecturas de Ratzel, quien estaba influenciado por el naturalista inglés. La dialéctica sería entre, por un lado, criollos y migrantes del sur de Europa, todos con visiones terrestres de la política y, por otro lado, pueblos anglosajones, esencialmente marítimos. Esta oposición parece ser continuadora de la misma visión peyorativa que sostuvo Alberdi en las Bases, donde rechazaba a criollos y migrantes de la península ibérica y hacía un llamado al fomento de la inmigración anglosajona, pueblo marítimo y comercial, más apto que el criollo para la libertad (Alberdi, 2009: 193) ${ }^{3}$.

\section{Su repercusión}

Las tesis de Storni han repercutido de forma indudable en el pensamiento naval posterior en Argentina. Hasta fines del siglo XIX, la visión de la Marina de Guerra se orientaba, sobre todo, a los ríos. La importancia que el Río de la Plata y el Paraná han tenido para la economía y la política argentina, la "guerra fluvial" librada en la Campaña del Paraná contra Gran Bretaña y Francia, más la consolidación tardía de la soberanía sobre la Patagonia y sus costas marítimas, llevó a que la mayoría de los esfuerzos se orientaran a la consolidación de la navegación fluvial mediante una flota adecuada y puertos en condiciones. Esto comenzó a cambiar a fines del siglo XIX, en gran medida, por la consolidación de la soberanía nacional sobre las costas patagónicas y por el crecimiento del comercio internacional. No obstante, fue recién con la publicación de Intereses argentinos en el mar que este nuevo objetivo se plasmó en una teoría geopolítica y una visión global y de largo alcance sobre la relación que debía tener Argentina con el mar (De Marco, 2010: 117-121).

Cutrona señala que la obra de Storni ejerció una "notable influencia en la doctrina militar marítima de Argentina" (Cutrona, 2011: 6, n. 7), aunque lamentablemente

\footnotetext{
${ }^{3}$ En el capítulo XXX, Alberdi afirma que "es necesario fomentar en nuestro suelo la población anglosajona. Ella está identificada con el vapor, el comercio y la libertad, y nos será imposible radicar estas cosas entre nosotros sin la cooperación activa de esa raza de progreso y de civilización” (Alberdi, 2009: 193).
} 
no establece cuál fue, en concreto, esa influencia. Por su parte, el general Molina Johnson sí señala una invención perdurable en la obra de Segundo Storni: el concepto de "Cono Sur" (Molina Johnson, 2000: 28), idea clave en la geopolítica de América del Sur y que será desarrollada por otros autores con posterioridad.

Algunas influencias del pensamiento de Storni en la marina argentina son resaltadas por Figueroa (2010). Empieza por afirmar que, en sus conferencias de 1916, Storni "plasmaba el pensamiento que caracterizaba a la cúpula naval en torno al papel articulador y orientador del Estado en el impulso de la actividad privada con características industrialistas" (Figueroa, 2010: 12-13; en el mismo sentido Delamer et al., 2011: 18). La postura de Storni se emparentaba con la de los capitanes de fragata Pedro Casal y Jorge Games y la del contraalmirante Manuel J. Lagos. Es decir, sus posturas, siendo novedosas en su formulación, eran parte del ideal colectivo de la marina. No obstante, es Storni el responsable de popularizarlas a través de las conferencias que no estaban dirigidas a un público especializado, sino a la divulgación de propuestas concretas.

Dichas propuestas parecen estar presentes en el pensamiento de Manuel Domecq García (Figueroa, 2010: 17), quien también postulaba la necesidad de crear una fuerte marina mercante nacional, mejorar las comunicaciones marítimas y explotar los recursos naturales, en combinación con la expansión de la marina de guerra y la instalación de bases militares en la Patagonia. Domecq García fue Ministro de Marina del presidente Torcuato Alvear (1922-1928) ${ }^{4}$. Durante su gestión puso en marcha algunas de las propuestas que Storni había considerado en sus conferencias y que Figueroa describe de forma muy halagüeña (Figueroa, 2010: 18-31). Para Figueroa, no sólo existe un parentesco entre el pensamiento de Storni y el de Domecq García, sino que el segundo sigue al primero y se inspira en sus tesis.

Por último, no puede obviarse el paso del vicealmirante por la alta política nacional. Segundo Storni fue Ministro de Relaciones Internacionales durante la primera etapa del gobierno surgido de la Revolución de 1943. Recordemos que aquella revolución estaba encabezada por un grupo de militares nacionalistas reunidos en el "Grupo de Oficiales Unidos" (GOU). En su seno militaba nada menos que el coronel Juan Domingo Perón, quien luego sería tres veces presidente de la Nación y la personalidad más influyente de la política argentina desde entonces.

\footnotetext{
${ }^{4}$ Marcelo Torcuato Alvear era parte de la Unión Cívica Radical, el partido que llevó al gobierno a Hipólito Yrigoyen en 1916. Éste último fue el primer presidente elegido por el voto universal, secreto y obligatorio, convirtiéndose en un caudillo popular. No obstante, debe tenerse en cuenta las profundas diferencias entre ambas personalidades (ver Galasso, 2012, t. II: 165 y ss.). En su texto, Figueroa lo pone de resalto: a Yrigoyen lo describe como un presidente que se valió de las Fuerzas Armadas para sostener su régimen político. Al contrario, a Alvear se lo muestra como impulsor de las reformas enumeradas en el texto. Aunque es una visión discutible de la historia, es cierto que es la lectura más común.
} 
A Storni no le fue bien en su carrera política. En gran medida sus ideas no se condecían con las que esgrimía el gobierno revolucionario y eso se comprobó rápidamente. Durante la Segunda Guerra Mundial, el vicealmirante era partidario de los aliados, al contrario del grupo de Perón, que era neutralista. La neutralidad implicaba una oposición frontal a la política de Estados Unidos que, luego de su ingreso en la contienda, quería ver a todo el continente en guerra con el Eje.

Durante el año 1944, el Secretario de Estado estadounidense, Cordell Hull, había radicalizado su presión sobre América Latina para incluir a todo el continente en la guerra. Storni, en respuesta a esta insistencia, envió al Departamento de Estado una nota confidencial en la que exponía, según cuenta Abelardo Ramos, "el amor secreto que el gobierno [argentino] acariciaba por las democracias" y le solicitaba "comprensión y paciencia" para la ruptura de relaciones con el Eje y la declaración de guerra (Ramos, 2013: 49).

La reacción de Hull fue imprevista para Storni y del todo nociva para ambos: publicó la nota del vicealmirante, dejándolo en ridículo y obligándolo a renunciar, ya que contradecía abiertamente la política nacional. Sin embargo, la actitud del Secretario de Estado derivó en grandes manifestaciones antiestadounidenses en Buenos Aires, a la par que obligó a Estados Unidos a reconocer que en la Casa Rosada había un gobierno contrario a su política, lo cual necesariamente debía derivar en sanciones y denuncias internacionales.

Este episodio muestra una confrontación que tarde o temprano iba a surgir. Los propios documentos del GOU previos a la Revolución del 4 de junio de 1943 contradecían la visión de Storni sobre las relaciones internacionales que Argentina debía adoptar. En efecto, un documento que según Robert Potash fue escrito por Perón en mayo de 1943 (un mes antes del golpe militar), afirmaba la necesidad de consolidar las relaciones con Chile, Brasil y Paraguay. El documento proponía un eje entre los tres países ya que, de lograrse, "la hegemonía sudamericana pasaría de nuevo a manos de la Argentina" (Potash, 1984: 196). ${ }^{5}$

Como veremos a continuación, Storni no buscaba la vinculación con países limítrofes como Paraguay, que poco podían darle a la Argentina, según su visión. Para Storni, al "mundo" se llegaba por mar y quedaba en Europa. En este sentido, la confrontación entre el vicealmirante y el gobierno que catapultaría al poder a Perón por vía democrática tres años después, no constituye sólo una anécdota biográfica. Al contrario, sirve para explicar el núcleo del pensamiento del vicealmirante, el cual se orientaba hacía relaciones mucho más cercanas con "el mundo" de lo que el peronismo estaba dispuesto a aceptar. De esto hablaremos en el próximo acápite.

\footnotetext{
${ }^{5}$ Esta idea se concretó durante las presidencias de Perón con el acuerdo denominado A.C.P. (Argentina, Chile, Paraguay). En 1953 el acuerdo se amplió con la incorporación de Bolivia (Santos Martínez, 1976, t. I: 302).
} 


\section{Argentina marítima}

De las conferencias editadas en Intereses argentinos en el mar, es particularmente importante subrayar la tesis central de la primera de ellas, la cual moldea el resto de la obra. El núcleo se encuentra en la creencia que Argentina sería una nación insular y, por tanto, marítima. La ubicación geográfica, el estar rodeado por mar y que "la distancia media que separa a esa casi isla del centro de gravedad de la civilización, ¡es no menor de diez mil kilómetros de vía totalmente marítima!" (Storni, 2009: 2829), hacen que nuestro destino sea el mar. Otra vez la influencia de Mahan se hace patente, ya que el autor de The influence of the sea power también hablaba del carácter insular de Estados Unidos (véase González Martín y Aznar FernándezMontesinos, 2013: 345-346).

Es evidente que alrededor de Argentina hay más que mar: están las naciones de América del Sur ${ }^{6}$. Sin embargo, para Storni $-\mathrm{y}$ a diferencia del documento del GOU arriba citado-, estos son "países con los cuales nos conviene hermanar esfuerzos, pero de los cuales poco podremos recibir" (Storni, 2009: 29). Es cierto que el vicealmirante argentino bregó por la unión con los países sudamericanos con costas al Atlántico (sobre todo Brasil y Uruguay) y al Pacífico (en especial Chile y Perú). No obstante, su objetivo principal está en eso que él llama el "centro de gravedad de la civilización", ya que "poco podremos recibir" de los países vecinos. A Brasil, Chile, Perú y Uruguay los veía más bien como bases marítimas para la flota mercante nacional que aspiraba a construir:

La amistad firme y mutua inteligencia con el Brasil y Uruguay, por un lado, y por el otro, con Chile y el Perú, es esencial: es como el punto de partida que asegurará los caminos para ambos lados de la América del Sur, no solamente por la acción local de las fuerzas propias, sino por la concurrencia y el apoyo de las fuerzas del vecino (Storni, 2009: 92).

Al tener como "principal y casi forzosa comunicación con el mundo, la vía marítima" (Storni, 2009: 33, destacado nuestro), Argentina necesitaba de los vecinos como bases navales para los buques del país. En el contexto del pensamiento de Storni, "mundo" significa Europa y Estados Unidos.

Esta orientación hacia el "centro de la civilización" y "el mundo" por vía marítima crea la necesidad de que Argentina tenga como centro de gravedad Buenos Aires, el gran puerto del país. Quizás influenciado por Ratzel, Storni parece hacer foco en lo que el geopolítico alemán llamaba "núcleo de desenvolvimiento de los

\footnotetext{
${ }^{6}$ Tampoco es cierto que nuestro país esté "rodeado" por mar, ya que Argentina, en momentos en que Storni pronuncia las conferencias, ya no podía reclamar salida al Pacífico. Esto en virtud del "Protocolo de límites entre Chile y Argentina" de 1893 firmado con posterioridad al Tratado de Límites de 1881.
} 
pueblos" (Ratzel, 1975: 15-52). Para el vicealmirante, éste debía necesariamente ser Buenos Aires, ya que la ciudad-puerto orientaba sus miras al "mundo" y no se quedaba atrapado por la tierra:

Las aldeas miserables, que no ciudades, sepulcros de vivos como las llamara Estrada, nacidas egoístas y aisladas en la conquista, presienten en Buenos Aires el centro atractivo del sistema, allí adivinan la luz y la riqueza. [...] En esa gran fuerza atractiva común reside una de las causas reales y permanentes de la unión nacional; ella hizo la unidad geográfica y por ende la unidad política (Storni, 2009: 43).

Segundo Storni no se cuestiona la primacía absoluta de Buenos Aires y las consecuencias que ha tenido para el desarrollo nacional. Sus propuestas se concentran en la defensa férrea del Río de la Plata, único canal para conectarse con "el mundo". Por supuesto que también brega por la construcción de puertos en la Patagonia, señalando detalladamente las ubicaciones y las razones geoestratégicas ${ }^{7}$. Sin embargo, no se pone en cuestión la supremacía de la Capital marítima frente a las "aldeas miserables" y "egoístas", sino que se le atribuye el hecho de ser la "fuerza atractiva común" de la unión nacional.

Es evidente que campea un criterio antropológico de distinción entre el hombre de la tierra y el hombre del mar, entre quienes habitan en el campo y quienes lo hacen en los puertos. Para Storni, un pueblo marítimo es un pueblo más evolucionado, más audaz e inteligente. El hombre de mar se encuentra en un estadio superior de la evolución, ya que se requieren conocimientos más elevados para navegar que para plantar la tierra. El hombre de la tierra constituye un "pueblo más dócil y menos aspirante" (Storni, 2009: 43). Para lanzarse al mar se requiere un "alto grado de civilización", si se busca obtener un "positivo beneficio y poco riesgo" (Storni, 2009: 53). Para cultivar la tierra "se requiere muchísima menos inteligencia, preparación y energía que para organizar una compañía de navegación o de pesquerías marítimas, o plantear un astillero" (Storni, 2009: 56). Es esta la razón por la que debe incentivarse una política naviera que incluya el servicio militar naval para que se pueda adquirir "ideas amplias y grandes en la mente popular, ahogada por el estrecho horizonte de tierra adentro y hecha por tradición a no ver la patria ni el mundo sino a través del humilde agujero lugareño" (Storni, 2009: 59). ¿Qué sucede si Argentina no puede convertirse en una potencia naval?: "será reconocer [...] que sobre nosotros pesa, en forma indeleble, el estigma de las razas inferiores" (Storni, 2009: 45). La incapacidad de crear un poder naval, tal que permita a la Argentina controlar por sí misma su comercio y defender los mares adyacentes, es síntoma de ser una raza inferior.

\footnotetext{
${ }^{7}$ En el acápite siguiente veremos las críticas de Guglialmelli a las propuestas de ubicación de los nuevos puertos
} 
Pero además de esto hay una razón que explica por qué deberíamos abandonar la tierra, tomar el mar y demostrar no ser una raza inferior. Es el comercio lo que más le interesa al vicealmirante. El tráfico mercantil deviene en casi único leitmotiv para la consolidación del poder naval. Segundo Storni comienza por hacer notar que la historia sólo se estudia bajo la influencia exclusiva de la "pluma y de la espada", y "las industrias que nacen y sus no menos meritorios autores y propagandistas o no se nombran o suenan de paso como pinceladas sin efectos en el gran cuadro" (Storni, 2009: 86). Storni quiere reconocer la centralidad histórica de las industrias, sus "autores y propagandistas".

De este papel fundamental surge la necesidad de proteger el comercio marítimo. Tanto es así que el autor de Intereses argentinos en el mar afirma que la defensa marítima "puede definirse así: asegurar la invulnerabilidad de la boca de los sectores comerciales, la franquicia de las vías y la permanencia del tonelaje de transporte" (Storni, 2009: 90). Las bases navales, los puertos, los submarinos, el servicio de vigilancia de aviones y guardacostas sirven para sostener la "boca de los sectores comerciales". La flota de mar de "considerable radio de acción" y con "puntos de apoyo en las rutas", todo esto sirve para proteger el comercio nacional, que es de materias primas agroexportables, algo que no busca cambiarse en las propuestas de Storni. Desarrollar una gran industria, para continuar comerciando granos y carnes, tal cual era el imaginario común de la época: Argentina, país agrícola, se dedicaría a la exportación de materias primas. El desarrollo industrial sólo sería importante en la medida en que beneficie dicha exportación.

En resumidas cuentas, el vicealmirante Segundo Storni plantea que Argentina es un país marítimo por excelencia, a la par que llama a aceptar nuestro destino insular y periférico para poder planificar una política naviera adecuada y tomar el mar como elemento vital. Esto va de la mano con una exaltación del hombre de mar en desmedro del trabajador de la tierra, el cual es menos audaz e inteligente que el naviero. Una elección por el mar hará del pueblo argentino un pueblo con mayores "miras", más apto y demostrará no ser de "raza inferior". Storni piensa que el núcleo de desenvolvimiento del pueblo argentino debe estar en Buenos Aires, ciudad-puerto cuya visión está puesta en las rutas marítimas hacia "el mundo" y no en el interior del país.

La finalidad última de la propuesta de Storni es el comercio marítimo. La protección y consolidación del poder naval argentino está directamente relacionada con la búsqueda de mejorar las rutas comerciales de Argentina en su contacto con los "centros de civilización". Es ese el objetivo primordial en su obra: la garantía de un seguro tráfico mercantil. La visión de Storni apunta al desarrollo económico mediante el intercambio comercial con "el mundo" y no por medio de un mercado interno fuerte. Argentina debe buscar alianzas económicas y políticas extracontinentales y no con países sudamericanos, que "poco pueden ofrecer". 


\section{La crítica de Guglialmelli}

La principal crítica a la posición de Storni proviene, no azarosamente, de un intelectual del ejército argentino: Juan Enrique Guglialmelli, quizás uno de los más prolíficos cultivadores de la geopolítica en nuestro país. No es azaroso que la crítica provenga del ejército, ya que las bases de la formación de ambas fuerzas difieren profundamente. La Marina de Guerra argentina tiene como principal influencia el pensamiento naval anglosajón y, sobre todo, británico. El Ejército argentino recibió, durante el siglo XIX, la poderosa influencia de las teorías francesas. Sin embargo, esto se revirtió radicalmente luego de la Guerra Franco-Prusiana. Desde ese momento, la principal fuente teórica de nuestro ejército fue alemana, lo cual se refleja con particular énfasis en el pensamiento de Juan Domingo Perón (véase, entre otros, Fernández Vega, 2005: 315 y ss.; Piñeiro Íñiguez, 2010: 164-165). Esto hacía que ambas armas contasen con visiones políticas y proyectos de país muchas veces contrapuestos $^{8}$.

En un texto publicado originalmente en la revista Estrategia, Guglialmelli controvierte la tesis de Storni en tres puntos fundamentales: i) el carácter insular de Argentina; ii) la omisión del vicealmirante de la estructura económica dependiente del país, y iii) la subestimación del mercado interno (Guglialmelli, 1979: 73).

El primer punto incluye el problema de la relación de Argentina con el resto de los países sudamericanos. Para el general, Storni, al considerar a nuestro país como una "isla", lo "divorcia" del continente. Argentina estaría separada y desprendida de Sudamérica. Al contrario, para Guglialmelli Argentina está unida a la región por "la geografía, la historia, la economía y el destino". Argentina es, "en la más amplia acepción geopolítica del término", peninsular: "mantiene su condición marítima pero asume también su rol continental" (Guglialmelli, 1979: 78).

Storni, según el general argentino, relega a Paraguay y Bolivia de toda consideración, dos naciones mediterráneas que necesitan de Argentina para obtener salida al mar (Guglialmelli, 1979: 73). El punto es importante y demuestra la conciencia americanista mayor de Guglialmelli por sobre Storni, quien fundamenta sus tesis en lo que él creía era el interés del país sin importar el de los vecinos. Como ya vimos, Uruguay, Brasil y Chile sólo interesan de forma instrumental para nuestro país (Guglialmelli, 1979: 73-74).

En cuanto a la política naval que debe seguir Argentina, Guglialmelli afirma que Storni "compartimenta el espacio nacional", ya que sólo pensó en la construcción de puertos a orillas del Atlántico, pero no previó comunicaciones terrestres entre los

\footnotetext{
${ }^{8}$ Un hecho histórico de absoluta trascendencia es buen ejemplo de ello: fue la Marina la que, por medio de su aviación, bombardeó la Plaza de Mayo en junio de 1955 buscando derrocar al gobierno del general Perón. Este acto es el comienzo del fin del gobierno peronista que se da, en complicidad con algunos elementos del Ejército, en septiembre de ese año.
} 
respectivos hinterlands. Es decir, estaba garantizada la comunicación con el "mundo", pero no la que debe darse al interior del país por vía terrestre. Además, para el general Guglialmelli, Storni subestima la importancia de los ríos Paraná y Uruguay, concentrándose únicamente en las vías navegables hacia los "centros de civilización", pero sin tomar en cuenta la centralidad geopolítica de la navegación fluvial interna al continente (Guglialmelli, 1979: 74).

El segundo y tercer punto abordan el aspecto político-económico, algo central en la crítica de Guglialmelli. Como dijimos, Storni parece adherir a la llamada "Generación del 80", la cual "tiene un basamento económico" en la "producción agropecuaria de la "pampa húmeda», inserta en la división internacional del trabajo". Storni, bajo esta perspectiva, no podía ver que Argentina era "la granja de Europa, en particular de Gran Bretaña", estando su economía basada en el cambio de "carnes, lanas y cereales por combustibles y productos manufacturados" (Guglialmelli, 1979: 75). La propuesta del vicealmirante consistía, básicamente, en reproducir esta dependencia económica, ya que su finalidad no era más que agilizar y proteger el comercio marítimo de materias primas. Todo el desarrollo industrial estaría orientado a esa finalidad y no al sostenimiento y desarrollo del mercado interno.

Guglialmelli le impugna a Storni no ver que lo más importante para Argentina es el desarrollo de "un fuerte y único mercado interno de producción y consumo". Esto se basa en razones de índole económica, pero también geopolíticas: "El mercado interno en expansión, resulta por otra parte el gran factor en la vertebración continental de la Argentina". Para el general, el pensamiento común de la geopolítica de América del Sur - en el cual se incluye a Storni-, se basa en una intercomunicación entre Estados pero con el único objetivo de construir "medios de circulación hacia los puertos". Los países del continente parecen sólo disputarse el "papel de zonas de tránsito", siendo que lo importante "son las posibilidades de expandir nuestro mercado interno" (Guglialmelli, 1979: 76).

En conclusión, lo que no habría visto Storni es que la consolidación del mercado interno y su vinculación con los países sudamericanos es la base para la formación de un bloque regional apto para insertarse en plano de igualdad en la economía mundial. La lógica del vicealmirante es más bien la contraria. Él mismo admite que los argentinos "hemos llegado ya tarde al banquete de la vida" (Storni, 2009: 91) y, por tanto, poco podemos hacer para rivalizar con las grandes potencias. En ese sentido se entiende mucho mejor su propuesta: mejor incentivar el comercio, haciendo foco en los puertos y en los caminos al mar para colocar nuestras materias primas. Al final, el banquete siempre se lo comerá otro.

\footnotetext{
${ }^{9}$ Se llama así a los políticos e intelectuales que actuaron y se formaron a partir de la primera presidencia de Julio Argentino Roca y que extendieron su influencia por varios años. A pesar de la crítica, Guglialmelli rescata el pensamiento industrialista de Carlos Pellegrini, presidente entre 1890 y 1892 y representante de la Generación.
} 


\section{La toma del mar y la desespacialización de la política}

Segundo Storni ocupa un lugar destacado en la geopolítica argentina. Hemos visto su influencia en el pensamiento naval del siglo XX y su huella en el desarrollo del potencial naviero durante la presidencia de Torcuato Alvear. Intereses argentinos en el mar sigue siendo un texto de referencia histórica importante y, a pesar de los avatares con el gobierno de la Revolución de 1943 —donde Perón ocupaba un lugar destacado-, fue justamente durante gobiernos peronistas que el libro se reeditó oficialmente (1952 y 2009).

No obstante, luego de este recorrido sobre la tesis central de la principal obra de Storni, pueden elaborarse algunas conclusiones que ubican a nuestro autor como parte de un pensamiento que tiende a la desespacialización de la política.

1. Como vimos, la posición del vicealmirante como teórico naval y sus influencias anglosajonas se llevan mal con ciertos sectores del Ejército argentino. La crítica de Guglialmelli es aleccionadora en este sentido y presenta dos visiones contrapuestas al interior de las fuerzas armadas del país. Sin embargo, lo central para nuestra lectura es notar que las bases políticas de Storni, a diferencia del general Guglialmelli, no se encuentran sólo en las doctrinas navales anglosajonas, sino en el modo de pensar de las potencias marítimas. Éstas, según la clásica distinción schmittiana en Tierra y mar, El nomos de la tierra y otros textos, disuelven la dimensión espacial de la política y la relación de los pueblos con la tierra.

Como dijo Hegel, la industria tiene al barco como elemento, que surca los mares y atraviesa fronteras, sin asentamiento propio. Storni, al basar su pensamiento en las comunicaciones comerciales hacia "el mundo", al considerar que Argentina es una isla y al no poner el foco en el mercado interno, estaba tomando partido por la desespacialización política que lleva ínsita la toma del mar (véase Schmitt, 2004, y Ruschi, 2009). La propuesta de dejar de ver la tierra al interior del país y a los vecinos sudamericanos haciendo foco en el comercio marítimo con "el mundo", derivaba en un pensamiento que desprendía al país del continente. Argentina debía tomar el mar y relacionarse comercialmente con "la civilización".

2. Desde el punto de vista económico la desespacialización se radicaliza, probándose lo que señala Carlo Galli: la economía capitalista es uno de los universales que disuelven los espacios políticos (Galli, 2002: 70). Es cierto que hay un pedido del vicealmirante por la industrialización en materia naval y la generación de una flota mercante y de guerra propia, lo cual supondría el desarrollo de industrias pesadas autosuficientes, con el consecuente impacto en el mercado interno. Sin embargo, Guglialmelli acierta en que, para Storni, esa flota sólo debía orientarse al comercio marítimo con "el mundo", reproduciendo las mismas lógicas que habían imperado desde la organización nacional en la segunda mitad del siglo XIX sin incentivar un mercado interno fuerte "vertebrador" de la unidad continental. Esto es también una muestra de que la tesis de Storni supone una deslocalización de nuestro 
país con el resto de Sudamérica. Los vecinos son vistos como bases navales que los barcos argentinos deberán utilizar en su camino "al mundo".

3. Lo anterior hace que Storni fije su atención en Buenos Aires como núcleo de desenvolvimiento nacional. Es justamente lo que Alejandro Bunge criticó en Una Nueva Argentina. Bunge observaba que en 1924, es decir, a menos de diez años de la publicación de las conferencias de Storni, en un arco de $780 \mathrm{~km}$ se asentaban ocho décimos de la población y nueve décimos de la capacidad económica del país. El autor trazó tres zonas en forma de arco que tenían como centro Buenos Aires. La primera con radio de $580 \mathrm{~km}$, la segunda en $1000 \mathrm{~km}$ y la tercera más allá de esta distancia. "La densidad de la población, la capacidad económica, el nivel cultural y el nivel de vida van disminuyendo a medida que aumenta la distancia de la Capital", Buenos Aires ha tomado la postura de mirar "hacia ultramar y con la espalda al interior" (Bunge, 1940: 233-234). Storni se olvida de lo que él llama "aldeas miserables", profundizando la situación que describiera Bunge. Como vimos, Storni llama a fijar la atención en Buenos Aires, como núcleo de desarrollo y supuesto centro de unidad nacional. La capital se separa del interior "miserable" y "egoísta". Con su búsqueda de tomar el mar y hacer foco en el puerto, no sólo deslocalizaba Argentina de Sudamérica: también separaba Buenos Aires del resto del país.

4. Todo lo dicho se relaciona con la concepción antropológica de Storni, quien marcaba una diferencia entre pueblos terrestres y pueblos marítimos. Nuestro autor llamaba a despertar la conciencia marítima del pueblo y a tomar el mar como elemento, abandonando la visión terrestre que crea hombres poco sagaces y avezados. Las propuestas del vicealmirante implican reformas en la educación, en el servicio militar y en los parámetros culturales. Se necesitaba un nuevo hombre para afrontar el desafío del siglo XX. En este sentido, su posición continúa la tradición liberal del siglo XIX, dedicada a contraponer lo criollo con lo extranjero y, por tanto, a importar maestros y educadores foráneos, fomentando "la inmigración europea", como reza la Constitución Nacional desde 1853 en su artículo 25. Aquí también se ve el proceso de desespacialización: si el tipo argentino no puede aceptar el universal económico que llama a romper con los espacios cerrados, entonces o se cambia su forma de pensar o se reemplaza al pueblo por otro.

\section{A modo de cierre}

Unas breves líneas para cerrar el escrito. Es cierto que pudieron y pueden extraerse aportes para la praxis política de la obra principal del vicealmirante. No negamos tampoco sus buenas intenciones a la hora de pronunciar sus propuestas políticas de incremento del poder naval y de consolidación de mecanismos para la defensa nacional. Sin embargo, nuestra lectura muestra que la toma del mar como elemento principal y la afirmación de que Argentina es una nación marítima e insular por naturaleza, profundiza un proceso de desespacialización de la política que, por 
supuesto, comenzó mucho antes y se da por diversas razones. El barco que surca los mares colocando el producto comercial, sin lugar fijo de asentamiento y sin visión del interior del país, es el elemento central del pensamiento geopolítico de Storni. Argentina se convierte en una isla separada del continente. Las naciones vecinas son puntos de apoyo a la navegación. Buenos Aires un puerto deslocalizado, sin conexión con lo que sucede a sus espaldas. El espacio político se disuelve con el barco que comercia los productos argentinos en el mundo, núcleo del pensamiento político de Storni.

\section{Bibliografía}

Alberdi, Juan Bautista (2009) Bases y puntos de partida para la organización política de la República Argentina. La Plata: Terramar.

Barrios, Miguel Ángel (dir.) (2009) Diccionario latinoamericano de seguridad y geopolítica. Buenos Aires: Biblios.

Bunge, Alejandro E. (1940) Una nueva Argentina. Buenos Aires: Hyspamerica.

Cutrona, Sebastián A. (2011) "Geopolítica: del estigma euroamericano al florecimiento en Latinoamérica". Inferencia política, UNLaR, núm. 1. [URL: $<\mathrm{http}$ ://inferenciapolitica.unlar.edu.ar/NUMEROUNO/Art\%C3\%ADculo\%20Cu trona.pdf $>$. Consultado el 12 de Agosto de 2014].

Delamer, Guillermo; Oyarzábal, Guillermo; Montenegro, Guillermo J.; Bergallo, Jorge, y Santillán, Haroldo (2011) "Evolución del pensamiento estratégico naval argentino a lo largo de la historia. Parte 2". Boletín del Centro Naval, núm. 829, 13-24.

[URL: $<$ http://www.centronaval.org.ar/boletin/BCN829/829SANTILLANYOTROS.pd f>. Consultado el 20 de Marzo de 2013].

De Marco, Miguel Ángel (2010) "De la Marina «fluvial» a la Marina «atlántica»", en O. Moreno (comp.) La construcción de la nación argentina. El rol de las fuerzas armadas. Debates históricos en el marco del bicentenario (1810-2010). Buenos Aires: Ministerio de Defensa de la República Argentina. [URL: $<$ http://www.mindef.gov.ar/publicaciones/pdf/Libro-La-construccion-de-la-

Nacion-Argentina-El-rol-de-las-Fuerzas-Armadas-AAVV.pdf $>$. Consultado el 12 de Octubre de 2014].

Fernández Vega, José (2005) Las guerras de la política. Clausewitz de Maquiavelo a Perón. Buenos Aires: Edhasa.

Figueroa, Mauro Fernando (2010) "El desarrollo naval argentino. Avances y retrocesos (1922-1938)". Revista Digital del Instituto Universitario Naval, vol. II, núm. $2, \quad 8-36 . \quad$ [URL: $<$ http://www.inun.edu.ar/menues/investigacion/revista/REVISTA\%20DIGITAL \%20DE\%20INVESTIGACI\%C3\%93N\%20DEL\%20INUN\%20N\%C2\%BA\%2 02.pdf $>$. Consultado el 12 de Marzo de 2014]. 
Galasso, Norberto (2012) Historia de la Argentina. Buenos Aires: Colihue.

Galli, Carlo (2002) Espacios políticos. La edad moderna y la edad global. Léxico de política [trad. Jorge Tula]. Buenos Aires: Nueva Visión.

Garré, Nilda (2009) "Presentación: actualidad del mensaje de Segundo Storni”, en S. Storni: Intereses argentinos en el mar. Buenos Aires: Armada Argentina. [URL: $<$ http://www.mindef.gov.ar/publicaciones/pdf/Libro-Intereses-Argentinos-en-elMar-Segundo-Storni.pdf $>$. Consultado el 10 de Enero de 2011].

González Martín, Andrés y Aznar Fernández-Montesinos, Federico (2013) "Mahan y la geopolítica". Geopolítica(s). Revista de estudios sobre espacio y poder, vol. 4, núm. $2 . \quad$ [URL: $<$ http://revistas.ucm.es/index.php/GEOP/article/view/46355/43575>. Consultado el 20 de Diciembre de 2014].

Guglialmelli, Juan E. (1979) " ¿Argentina insular o peninsular? (Reflexiones geopolíticas en torno al pensamiento del vicealmirante Segundo Storni)", en J. E. Guglialmelli: Geopolítica del Cono Sur. Buenos Aires: El Cid Editor.

Mahan, Alfred T. (1890) The influence of sea power upon the history, 1660-1783. Boston: Little Brown and Company.

Molina Johnson, Carlos (2000) "Cooperación regional: Potencialidades y limitaciones desde la perspectiva de la defensa nacional”. FASOC, vol. 15, núm. 2, 26-38. [URL: <http://www.fasoc.cl/files/articulo/ART4111081404c59.pdf>. Consultado el 12 de Marzo de 2014].

Piñeiro Íñíguez, Carlos (2010) Perón: la construcción de un ideario. Buenos Aires: Siglo XXI.

Potash, Robert A. (1984) Perón y el GOU. Los documentos de una logia secreta [compilación, introducción y comentarios de Robert Potash]. Buenos Aires: Sudamericana.

Ramos, Jorge Abelardo (2013) Revolución y contrarrevolución en la Argentina. La era del peronismo (1943-1946). Buenos Aires: Editorial Continente.

Ratzel, Friedrich (1975) "Ubicación y Espacio", en AA VV: Antología Geopolítica. Buenos Aires: Pleamar.

Ruschi, Filippo (2009) El nomos del mar. Espacio, derecho y hegemonía en Carl Schmitt [trad. Pablo D. Eiro]. Buenos Aires: Ad-Hoc.

Santos Martínez, Pedro (1976) La nueva Argentina, 1946-1955. Buenos Aires: La Bastilla.

Schmitt, Carl (2004) Tierra y mar: Consideraciones sobre la historia universal [trad. Rafael Fernández-Quintanilla, Centro de Estudios Constitucionales, Madrid, 1952], en H. O. Aguilar (prólogo y selección de textos) Carl Schmitt, teólogo de la política. México D. F.: Fondo de Cultura Económica.

Storni, Segundo (1916 [2009]) Intereses argentinos en el mar. Buenos Aires: Armada Argentina. [Edición digital en URL: $<$ http://www.mindef.gov.ar/publicaciones/pdf/Libro-Intereses-Argentinos-en-elMar-Segundo-Storni.pdf $>$. Consultado el 13 de Diciembre de 2014]. 